\title{
Correction to: Evaluation of the effects of miRNAs in familial Mediterranean fever
}

\author{
Hacer Orsdemir Hortu ${ }^{1} \cdot$ Emin Karaca $^{2} \cdot$ Betul Sozeri $^{3} \cdot$ Nesrin Gulez $^{4} \cdot$ Balahan Makay $^{5} \cdot$ Cumhur Gunduz $^{6}$. \\ Tahir Atik ${ }^{1} \cdot$ Ismihan Merve Tekin ${ }^{2} \cdot$ Sevket Erbil Unsal ${ }^{5} \cdot$ Ozgur Cogulu $^{2}$
}

Published online: 7 January 2019

(C) International League of Associations for Rheumatology (ILAR) 2019

\section{Correction to: Clinical Rheumatology \\ https://doi.org/10.1007/s10067-017-3914-0}

The original version of this article, unfortunately, contained errors.

The name of the last author of this article was incorrectly presented as "Cogulu Ozgur" this should have been "Ozgur Cogulu".

The original article has been corrected.

The online version of the original article can be found at https://doi.org/ 10.1007/s10067-017-3914-0

\section{Emin Karaca}

karacaemin@gmail.com

1 Faculty of Medicine, Department of Pediatrics, Ege University, Izmir, Turkey

2 Faculty of Medicine, Department of Medical Genetics, Ege University, Izmir, Turkey

3 Istanbul Umraniye Training and Research Hospital, Istanbul, Turkey

4 Izmir Dr. Behcet Uz Children's Diseases and Surgery Training and Research Hospital, Izmir, Turkey

5 Faculty of Medicine, Department of Pediatrics, 9 Eylul University, Izmir, Turkey

6 Faculty of Medicine, Department of Medical Biology, Ege University, Izmir, Turkey 